\title{
The Effects of Magnetic Nanoparticles Incorporated in Polyelectrolyte Capsules
}

\author{
CARMEN STAVARACHE ${ }^{1,2 *}$, MIRCEA VINATORU ${ }^{3}$, TIMOTHY MASO N², LARYSA PANIWNYK ${ }^{2}$ \\ ${ }^{1}$ Costin D. Nenitescu Institute of Organic Chemistry, 202B Splaiul Independentei, Bucharest, 060023, Romania \\ ${ }^{2}$ Faculty of Health and Life Sciences, Coventry University, Coventry, Priory Street, West Midlands, CV1 5FB, Coventry, United \\ Kingdom \\ ${ }^{3}$ Sonochem Cente Ltd., Bank Gallery, High Street, Kenilworth, CV8 1LY, United Kingdom
}

\begin{abstract}
Polyelectrolyte multilayer capsules are synthesized comprising of 12 total layers each containing a single layer of iron oxide nanoparticles in shells 4, 6, 8 or 10. A protein-labelled dye is embedded in the calcium carbonate template core as a model for the encapsulation of a drug. The core is dissolved after 6 layers are formed. Two types of magnetic nanoparticles are incorporated into various capsule shells: ferric oxide $\left(\mathrm{Fe}_{2} \mathrm{O}_{3}, 50 \mathrm{~nm}\right)$ and iron oxide $\left(\mathrm{Fe}_{3} \mathrm{O}_{4}, 15 \mathrm{~nm}\right)$, a 1:1( $\left.\mathrm{vol}.\right)$ mixture of the two types of nanoparticles suspensions is also used. Nanoparticle inclusion reduces the capsule sizes in all cases with the order of effect $\mathrm{Fe}_{3} \mathrm{O}_{4}<$ $\mathrm{Fe}_{2} \mathrm{O}_{3}<\mathrm{Fe}_{2} \mathrm{O}_{3} / \mathrm{Fe}_{3} \mathrm{O}_{4}$ mixture. When $\mathrm{Fe}_{3} \mathrm{O}_{4}$ Or a Fe $\mathrm{F}_{3} / \mathrm{Fe}_{3} \mathrm{O}_{4}$ mixture is incorporated in layer 6 the reduction in size of the final capsules is less than expected. The number of surviving capsules containing nanoparticles are lower than control regardless of which of the nanoparticles is used but here the effect of $\mathrm{Fe}_{3} \mathrm{O}$ or a mixture of the two types of nanoparticles incorporated in layer 6 was slightly out of step. The amount of iron incorporated is almost the same regardless of which shell the nanoparticles were incorporated but the iron content using $50 \mathrm{~nm}$ nanoparticles is generally slightly higher than that obtained with $15 \mathrm{~nm}$ nanoparticles.
\end{abstract}

Keywords: polyelectrolyte capsules, magnetic nanoparticles, drug encapsulation

When drugs are administered orally or by subcutaneous injection their effects are dissipated and not concentrated entirely in the infected area. This can lead to unwanted and sometimes unpleasant side-effects. If the drugs introduced into the body can be protected whilst en route to the infected part of the body and released at this target point this will reduce side effects and maximize the effective dosage received in the affected zone of the body. This is of particular importance for chemotherapy and is the reason why efforts are concentrated on finding an appropriate capsule material to use as a delivery system. Drugs that are incorporated in the capsules can then be released into the target area by breaking the capsules to release the drugs. Several systems that might provide such coatings for drugs including liposomes, block copolymers, dendrimers and polyelectrolyte multilayers have been investigated [1-3]. The last of these, polyelectrolyte multilayers, was used some 20 years ago for coating planar surfaces [4], but the process was soon extended to spherical particles [5]. The principle behind the fabrication of polyelectrolyte multilayers is a layer-by-layer ( $\mathrm{LbL}$ ) technique and consists of the deposition of alternating layers of oppositely charged materials over a sacrificial template, with wash steps in between [6]. The number of layers and their composition can be varied [7].

Pairs of synthetic polyelectrolytes like poly(styrenesulfonate) (PSS)/poly(allylamine) (PAH) and PSS/ poly(diallyldimethylammonium chloride) (PDADMAC) show linear growth behaviour during the buildup of layers while combinations of biopolymers like hyaluronic acid (HA)/poly-L-lysine (PLL) or poly(L-glutamic acid) (PGA)/ PLL grow exponentially [8]. One of the more popular multilayer systems is PAH/PSS being somew hat more rigid and stable than PDADMAC/PSS and with a higher elastic modulus [9]. It also presents a much greater barrier to ion transport and fewer capsules are broken due to swelling during template removal in the case of PAH than PDADMAC
[10]. PSS/PAH capsule preparation is reproducible and does not suffer from capsules aggregation [11]. Hollow capsules can be prepared using either organic templates (polystyrene, melamine formaldehyde) or inorganic carbonates and silica. It is possible to load porous $\mathrm{CaCO}_{3}$ with macromolecules/e.g. proteins and when such a material is used as a template for capsule fabrication, the macromolecules remain within the capsule when the $\mathrm{CaCO}_{3}$ is dissolved out. This technique can be used to generate protein filled polyelectrolyte capsules [12].

Currently, a large number of materials have been encapsulated in polyelectrolytes including DNA [13], proteins [14], lipids [15] and nanoparticles [16]. The nature of polyelectrolyte assemblies is such that they can be made responsive (in terms of break-down or permeability) to a range of external stimuli such as $\mathrm{pH}$, ionic strength, temperature, ultrasound, etc. [17].

Various types of nanoparticles have been incorporated into the shells of polyelectrolyte capsules by substituting one or more polyelectrolyte layers with species of the same charge [16-21]. Koleshnikova prepared polyelectrolyte capsules containing several layers of ZnO nanoparticles. The mechanical properties of the capsules were influenced by the variation of the volume fraction of $\mathrm{ZnO}$ nanoparticles added. Higher number of embedded nanoparticles leads to a decrease in shell elasticity, thus the capsules were made to be more susceptible to rupture under ultrasonic irradiation ( $20 \mathrm{kHz}, 40 \mathrm{~W})$ [22]. Therefore, by choosing the appropriate nanoparticles one can control the capsules properties.

The aim of this work was to prepare PSS/PAH microcapsules of differing sizes and susceptibility to disruption with ultrasound. Magnetic nanoparticles were inserted into different coating layers to assess their effects on capsule size and stability and also to be used at a later stage for magnetic driven transportation within the body. Protein (Bovine Serum Albumin (BSA)) and a dye Rhodamine B Isothiocyanate (RBITC)) were used as a

*email stavarachec@yahoo.com; Phone: +40213167900 
model for a drug incorporated into the core of the capsules.

\section{Experimental part}

Materials and methods

Poly(styrene sulfonate) (PSS, 70kDa), poly(allylamine hydrochloride) (PAH, 15kDa), Rhodamine B Isothiocyanate (RBITC), calcium chloride, sodium carbonate, sodium chloride, Bovine Serum Albumin (BSA) ethylene-diaminetetra-acetic acid (EDTA) iron oxide $\left(\mathrm{Fe}_{2} \mathrm{O}_{3}-50 \mathrm{~nm}\right)$ were purchased from Sigma-Aldrich. Super paramagnetic iron oxide $\left(\mathrm{Fe}_{3} \mathrm{O}_{4}-15 \mathrm{~nm}\right)$ was purchased from Skyspring Nanomaterials Inc, Houston, USA. All chemicals were used as received and Milli Q Plus water was used in all experiments.

\section{Capsule Preparation}

Fluorescent-labelled BSA was prepared by mixing 100 $\mathrm{mg}$ of BSA with $40 \mathrm{~mL}$ borate buffer $(\mathrm{pH}$ 9) and $1 \mathrm{mg}$ of RBITC dissolved in $5 \mathrm{~mL}$ of ethanol for $12 \mathrm{~h}$ followed by 72 $\mathrm{h}$ dialysis against distilled water. Fluorescent-labelled BSA was captured within the $\mathrm{CaCO}_{3}$ template core, prepared in situ by precipitation: $4 \mathrm{~mL}$ of BSA-RBITC solution was magnetically mixed with $10 \mathrm{~mL}$ of $0.33 \mathrm{M}$ calcium chloride solution for $5 \mathrm{~min}$ at room temperature at $1000 \mathrm{rpm} .10$ $\mathrm{mL}$ of $0.33 \mathrm{M}$ sodium carbonate solution was added dropwise in one minute and the mixture was stirred for 5 min at room temperature. The solution was centrifuged at $5000 \mathrm{rpm}$ for $5 \mathrm{~min}$ and the supernatant was discarded. The precipitate was washed with distilled water twice.

A solution of PAH ( $18 \mathrm{~mL}$ of $0.2 \mathrm{M}$ in $0.5 \mathrm{M}$ sodium chloride) was added to the core precipitate and the mixture was stirred at room temperature for 15 min then centrifuged and the supernatant discarded. The precipitate was washed with distilled water twice.

A solution of PSS ( $18 \mathrm{~mL}$ of $0.2 \mathrm{M}$ in $0.5 \mathrm{M}$ sodium chloride) was added to the previous precipitate and the mixture was magnetically stirred (1000 rpm) at room temperature for 15 min then centrifuged and the supernatant discarded. The precipitate was washed with distilled water twice. Thus, the core particles were coated with two layers of oppositely charged polyelectrolyte making one polyelectrolyte bilayer (PAH/PSS). Coating of the capsules continued up to a total of 12 layers.

The calcium carbonate template core was dissolved after the deposition of six layers by mixing with chelating reagent EDTA ( $10 \mathrm{~mL}, 0.2 \mathrm{M}$ solution) for $10 \mathrm{~min}$ followed by washing. The remaining 6 layers were added and the final capsules which were then suspended in $20 \mathrm{~mL}$ of distilled water and analyzed.

\section{Addition of nanoparticles}

$62.5 \mathrm{mg}$ ferric oxide nanoparticles $\left(\mathrm{Fe}_{2} \mathrm{O}_{3} 50 \mathrm{~nm}\right.$ ) were dispersed in $250 \mathrm{~mL} 0.5 \mathrm{M}$ sodium chloride solution (in a conical flask) and suspended by sonication in an ultrasonic bath (Langford Sonomatic, $575,40 \mathrm{kHz}, 150$ W power) for $30 \mathrm{~min} .0 .142 \mathrm{~mL}$ of super paramagnetic iron oxide nanoparticles $\left(\mathrm{Fe}_{3} \mathrm{O}_{4}, 15 \mathrm{~nm}\right)$ suspension at a concentration of $440 \mathrm{~g} / \mathrm{L}$ were mixed with $250 \mathrm{~mL}$ of $0.5 \mathrm{M}$ sodium chloride solution (in a conical flask) and suspended by sonication in an ultrasonic bath (Langford Sonomatic, $575,40 \mathrm{kHz}$, $150 \mathrm{~W}$ power) for $30 \mathrm{~min}$. The mixed suspension was made up from equal parts of the two $\mathrm{NaCl}$ suspensions making up the same volume as the individual suspensions. Each of the three suspensions ( $15 \mathrm{~mL}$ ) were used to form a layer of nanoparticles on a positively charged PAH layer of the partially formed capsule. This was followed by a PSS layer made with half of the amount used for the normal PSS layer. The two layers (nanoparticles plus thin PSS) were counted as the equivalent of 1 whole capsule layer. This composite layer was particularly important as layer 6 just before core removal because the PSS helped to keep the nanoparticles from being displaced during core dissolution. Subsequent layers beginning with PAH were built normally onto this composite layer.

\section{Analysis \\ Capsules Size Distribution}

A Malvern Multisizer 2000 laser diffractometer with a Hydro 2000MU attachment was used to measure the particle size distribution of various capsules prepared by our standard protocol in the diameter range $0.38-500 \mu \mathrm{m}$.

\section{Capsules Concentration}

The capsule suspension was diluted with distilled water in a ratio of 1:10 and the capsules were counted using a hemocytometer.

Iron Content

The capsules suspension $(2 \mathrm{~mL}$ ) was digested in $5 \mathrm{~mL}$ hot $\mathrm{HNO}_{3}$ : $\mathrm{HCl}$ solution ( $\left.1: 1 \mathrm{v} / \mathrm{v}\right)$ for $15 \mathrm{~min}$, and the iron concentration was determined using an Inductively Coupled Plasma Optical Emission Spectrometer (ICP-OES) Perkin Elmer Optima 5300DV.

\section{Results and discussions}

In all cases the capsules were constructed of 12 layers and the template core was removed after it had been coated with six layers. The capsules were given magnetic properties by incorporating either super paramagnetic iron oxide $\left(\mathrm{Fe}_{3} \mathrm{O}_{4}\right.$, magnetite, $\left.15 \mathrm{~nm}\right)$ or ferric oxide $\left(\mathrm{Fe}_{2} \mathrm{O}_{3} 50\right.$ $\mathrm{nm}$ ) as a layer in their shell structure in place of negatively charged PSS. A further set of capsules were prepared using a $\mathrm{Fe}_{2} \mathrm{O}_{3} / \mathrm{Fe}_{3} \mathrm{O}$ mixture of the two types of nanoparticles.

Core dissolution was carried out when 6 shells had been established. These comprised of either 6 polyelectrolyte layers or 5 polyelectrolytes and a composite (nanoparticle with thin PSS) layer. It had been established previously that six layers provided enough stability for capsules to remain intact following core dissolution using EDTA [23]. The reactions involved in core dissolution generate $\mathrm{CO}_{2}$ which can escape through defects (similar to pores) in the surrounding shells [22]. After core dissolution, six additional layers of either polyelectrolytes or 5 polyelectrolytes and one composite layer were added to form a total of 12 layers which ensured sufficient stability for further studies of the completed capsule. Capsules comprising of 12 polyelectrolyte layers and no nanoparticles were used as control.

\section{The Effect of Nanoparticles on Capsule Size \\ Using $15 \mathrm{~nm} \mathrm{Fe} \mathrm{O}_{4}$.}

The mean diameter for capsules containing $15 \mathrm{~nm} \mathrm{Fe}_{3} \mathrm{O}_{4}$ in different layers are shown (table 1 ).

When $\mathrm{Fe}_{3} \mathrm{O}_{4}$ is introduced into layers 4, 8 and 10 the capsule sizes are all similar but smaller than the control. However, when the nanoparticles are in the $6^{\text {th }}$ layer the capsule size is larger than that of the control. Nanoparticles in the $6^{\text {th }}$ layer are close to the surface and coated with only a small PSS layer. This is a somewhat different situation from the other types of capsule where the core is dissolved after 6 layers and the outer 2 layers consist of polyelectrolytes. The results suggest that an outer layer of $15 \mathrm{~nm}$ nanoparticles plus PSS is less permeable for the escape of $\mathrm{CO}_{2}$ produced during core dissolution than polyelectrolytes alone. In this case the $\mathrm{CO}_{2}$ is retained more within the capsule causing expansion of the 6-layer capsule 
- similar to the inflation of a balloon. Subsequent layers built onto this will lead to a larger final capsule.

In all other cases, the addition of nanoparticle layers reduces the final capsule size compared with control. Similar shrinking effects were reported by other groups [ 8 , $10,21]$

Using $50 \mathrm{~nm} \mathrm{Fe} \mathrm{O}_{3}$.

The mean diameters for capsules containing $50 \mathrm{~nm}$ $\mathrm{Fe}_{2} \mathrm{O}_{3}$ in different layers are shown (table 1).

In all cases the capsule sizes are smaller than that of the control but the sizes increase reasonably evenly as the $50 \mathrm{~nm}$ iron oxide layer is incorporated into the 4, 6, 8 and $10^{\text {th }}$ layer. In the $10^{\text {th }}$ layer they are approaching the diameter of control.

In contrast to capsules containing $15 \mathrm{~nm} \mathrm{Fe} \mathrm{O}_{4}$ there is no anomalous result for $50 \mathrm{~nm} \mathrm{Fe}{ }_{2}$ nanoparticles in layer 6 . This suggests that the $50 \mathrm{~nm} \mathrm{Fe}_{2} \mathrm{O}_{3}$ particles with a coating of PSS behave in a similar way, in terms of porosity to $\mathrm{CO}_{2}$, as do polyelectrolyte shells. A possible explanation lies in the calculated volumes of the two types of nanoparticle (assumed that they are spherical) which are $\sim 523,598.77 \mathrm{~nm}^{3}$ for $50 \mathrm{~nm}$ and $\sim 14,137.17 \mathrm{~nm}^{3}$ for 15 $\mathrm{nm}$ i.e. approximately 37 fold different. This should lead to different packing in the capsule shells with the $\mathrm{Fe}_{2} \mathrm{O}_{3}$ giving larger pores within the shell and therefore enabling easier escape of $\mathrm{CO}_{2}$ from the core during dissolution.

Using a 1:1 mixture of $15 \mathrm{~nm} \mathrm{Fe} \mathrm{O}_{4}$ and $50 \mathrm{~nm} \mathrm{Fe}_{2} \mathrm{O}_{3}$.

The mean diameters for capsules containing a combination of nanoparticles ( $15 \mathrm{~nm}$ and $50 \mathrm{~nm} \mathrm{1/1} \mathrm{v/v)}$ are shown (table 1).

When a combination of iron oxide nanoparticles ( 15 $\mathrm{nm}$ and $50 \mathrm{~nm} \mathrm{1/1} \mathrm{v/v)} \mathrm{is} \mathrm{used} \mathrm{the} \mathrm{results} \mathrm{are} \mathrm{similar,}$ although with smaller sizes, to those obtained with $15 \mathrm{~nm}$ $\mathrm{Fe}_{3} \mathrm{O}_{4}$ (Table 1). Once again in layer 6 where the capsule sizes are larger than expected we can surmise that the smaller nanoparticles fill in any gaps left by the larger nanoparticles and effectively reduce shell porosity below that of a polyelectrolyte layer.

\begin{tabular}{|c|c|c|c|}
\hline \multirow{2}{*}{$\begin{array}{c}\text { Location of } \\
\text { nanoparticles }\end{array}$} & \multicolumn{3}{|c|}{ Type of nanoparticles } \\
\cline { 2 - 4 } & $\mathrm{Fe}_{3} \mathrm{O}_{4} \mathbf{1 5} \mathbf{~ n m}$ & $\mathrm{Fe}_{2} \mathrm{O}_{3} \mathbf{5 0} \mathbf{~ n m}$ & $\mathrm{Fe}_{3} \mathrm{O}_{4} / \mathrm{Fe}_{2} \mathrm{O}_{3}$ mixture \\
\hline control & $6.65 \pm 0.94$ & $6.65 \pm 0.94$ & $6.65 \pm 0.94$ \\
\hline $4^{\text {th layer }}$ & $6.14 \pm 0.04$ & $5.49 \pm 0.42$ & $4.49 \pm 0.45$ \\
\hline $6^{\text {th }}$ layer & $6.91 \pm 1.88$ & $5.79 \pm 0.71$ & $5.72 \pm 2.04$ \\
\hline $8^{\text {th } l a y e r}$ & $6.11 \pm 0.78$ & $6.06 \pm 1.17$ & $4.38 \pm 1.12$ \\
\hline $10^{\text {th }}$ layer & $6.14 \pm 0.38$ & $6.50 \pm 0.65$ & $4.81 \pm 0.89$ \\
\hline
\end{tabular}

\begin{tabular}{|c|c|c|c|}
\hline \multirow{2}{*}{$\begin{array}{c}\text { Location of } \\
\text { nanoparticles }\end{array}$} & \multicolumn{3}{|c|}{ Mil. Capsules/ml suspension } \\
\cline { 2 - 4 } & $\mathrm{Fe}_{3} \mathrm{O}_{4} 15 \mathbf{~ n m}$ & $\mathrm{Fe}_{2} \mathrm{O}_{3} \mathbf{5 0} \mathbf{~ n m}$ & $\mathrm{Fe}_{3} \mathrm{O}_{4} / \mathrm{Fe}_{2} \mathrm{O}_{3}$ mixture \\
\hline control & $392 \pm 88$ & $392 \pm 88$ & $392 \pm 88$ \\
\hline $4^{\text {th }}$ layer & $382 \pm 45$ & $352 \pm 51$ & $308 \pm 62$ \\
\hline $6^{\text {th }}$ layer & $315 \pm 31$ & $345 \pm 49$ & $191 \pm 40$ \\
\hline $8^{\text {th layer }}$ & $371 \pm 18$ & $272 \pm 66$ & $237 \pm 32$ \\
\hline $10^{\text {th }}$ layer & $359 \pm 59$ & $302 \pm 97$ & $275 \pm 19$ \\
\hline
\end{tabular}




\begin{tabular}{|c|c|c|c|}
\hline \multirow{2}{*}{$\begin{array}{c}\text { Location of } \\
\text { nanoparticles }\end{array}$} & \multicolumn{3}{|c|}{ Iron content ( $\mu \mathrm{g} / 10^{10}$ capsules) } \\
\cline { 2 - 4 } & $\mathrm{Fe}_{3} \mathrm{O}_{4} \mathbf{1 5} \mathbf{n m}$ & $\mathrm{Fe}_{2} \mathrm{O}_{3} \mathbf{5 0} \mathbf{~ n m}$ & $\mathrm{Fe}_{3} \mathrm{O}_{4} / \mathrm{Fe}_{2} \mathrm{O}_{3}$ mixture \\
\hline $4^{\text {th }}$ layer & $0.70 \pm 0.08$ & $1.00 \pm 0.07$ & $1.11 \pm 0.12$ \\
\hline $6^{\text {th }}$ layer & $0.74 \pm 0.10$ & $0.83 \pm 0.08$ & $1.20 \pm 0.16$ \\
\hline $8^{\text {th }}$ layer & $0.75 \pm 0.12$ & $1.02 \pm 0.05$ & $1.16 \pm 0.15$ \\
\hline $10^{\text {th }}$ layer & $0.72 \pm 0.08$ & $1.16 \pm 0.07$ & $0.96 \pm 0.25$ \\
\hline
\end{tabular}

Table 3

IRON CONTENT ( $\mu \mathrm{g} / 10^{10}$ CAPSULES) IN VARIOUS TYPES OF CAPSULES
When the nanoparticles are mixed and used as one layer the results are similar but more pronounced than those obtained with $\mathrm{Fe}_{3} \mathrm{O}_{4} 15 \mathrm{~nm}$ particles alone (table 2). The number of surviving fully-formed capsules is lower than control in all cases. As with $\mathrm{Fe}_{3} \mathrm{O}_{4}$ incorporation into the $6^{\text {th }}$ layer the mixture gives the lowest yield which can again be ascribed to the smaller nanoparticles filling in any gaps left by the larger nanoparticles and thus leading to more strain in the capsules land consequently greater losses.

\section{Iron content of capsules}

The iron content in the polyelectrolyte capsules was determined by ICP-OES, after complete chemical breakdown of the capsules and acid digestion. The results are presented in tables 7-9. The values of iron are normalized to 100 million $\left(10^{10}\right)$ capsules taking into consideration the concentration of capsules in suspension.

Capsules Containing $15 \mathrm{~nm} \mathrm{Fe} \mathrm{O}_{4}$ Nanoparticles

The results for capsules containing $15 \mathrm{~nm}$ iron oxide nanoparticles are given in the table 3.

The iron distribution related to the position of nanoparticles in the capsule's layer is almost constant. This is perhaps surprising until it is recognised that the figures reflectiron content in surviving capsules. The similar value for iron content with nanoparticles in the 6th layer suggests little iron is lost during dissolution of the core for those capsules that survive the shell building process.

\section{Capsules Containing $50 \mathrm{~nm} \mathrm{Fe} \mathrm{O}_{3}$ Nanoparticles}

The results for capsules containing $50 \mathrm{~nm}$ iron oxide nanoparticles are given in the table 3 .

The iron content using $50 \mathrm{~nm}$ nanoparticles is generally higher than that obtained with $15 \mathrm{~nm}$ nanoparticles. Unlike the reasonably similar iron content observed when $15 \mathrm{~nm}$ iron oxide nanoparticles are incorporated into different shells (table 3 ) the retention of $50 \mathrm{~nm} \mathrm{Fe} \mathrm{O}_{3}$ nanoparticles in layer 6 is significantly worse than in other layers. This can be explained if there is a loss of these larger nanoparticles from shell 6 during core dissolution i.e. they are not so well secured as are the $15 \mathrm{~nm}$ particles by the diluted coating of PSS. Table 2 shows that there is no significant break-down of the capsules as a result of the loss of iron.

Capsules Containing Mixture of Nanoparticles

The results for capsules containing a mixture of iron oxide nanoparticles are given in the table 3 .

When mixed nanoparticles were used the infilling of smaller nanoparticles between the bigger nanoparticles appears to produce a more resilient coating compared with larger particles alone. This is most evident on 6th layer where the iron content was significantly higher.

\section{Leaching of BSA-labelled RBITC}

It has been previously reported that due to defects in the structure, encapsulated species in polyelectrolyte capsules can leak out [23]. It was therefore anticipated that during each step of coating some of the RBITC dye would leach from the capsules, with a maximum leakage anticipated at core dissolution. Fluorometric measurements were carried out in order to estimate the amount of the protein labelled dye escaped from the capsules. However, leaching of BSA-labelled RBITC needs further investigation and it will be discussed in a forthcoming paper.

\section{Conclusions}

Polyelectrolyte microcapsules composed of 12 sequential poly(styrene sulfonate) rene sulfonate (PSS) and poly(allylamine hydrochloride) (PAH) layers were synthesised on a $\mathrm{CaCO}_{3}$ core. A single shell of magnetic nanoparticles ( $\mathrm{Fe}_{2} \mathrm{O}_{3}, 50 \mathrm{~nm}, \mathrm{Fe}_{3} \mathrm{O}_{4}, 15 \mathrm{~nm}$ or a $\mathrm{Fe}_{2} \mathrm{O}_{3} / \mathrm{Fe}_{3} \mathrm{O}_{4}$ mixture) was introduced at layers $4,6,8$ and 10 . The core, containing a protein-labelled dye as a model for a drug, was removed after 6 coatings of only polyelectrolytes or polyelectrolytes and a single shell of iron oxide nanoparticles (in layers 4 and 6 ). After core dissolution 6 further polyelectrolyte layers were added with the option of nanoparticles in layers 8 or 10. The resulting capsules were analyzed in terms of their size, iron content and the number of capsules surviving the synthetic procedures.

The capsule sizes were reduced by the inclusion of a nanoparticle shell in all cases with the order of effect $\mathrm{Fe}_{3} \mathrm{O}_{4}$ $<\mathrm{Fe}_{2} \mathrm{O}_{3}<\mathrm{Fe}_{2} \mathrm{O}_{3} / \mathrm{Fe}_{3} \mathrm{O}_{4}$ mixture. When $\mathrm{Fe}_{3} \mathrm{O}_{4}$ or a $\mathrm{Fe}_{2} \mathrm{O}_{3} \mathrm{I}$ $\mathrm{Fe}_{3} \mathrm{O}_{4}$ mixture was incorporated in layer 6 the reduction in size of the final capsules was less than expected. The number of surviving capsules containing nanoparticles was lower than control regardless of which of the nanoparticles were used but here the effect of $\mathrm{Fe}_{3} \mathrm{O}_{4}$ or a $\mathrm{Fe}_{2} \mathrm{O}_{3} / \mathrm{Fe}_{3} \mathrm{O}_{4}$ mixture incorporated in layer 6 was slightly out of step. The amount of iron incorporated was almost the same regardless of which shell the nanoparticles were incorporated but the iron contentusing $50 \mathrm{~nm}$ nanoparticles was generally slightly higher than that obtained with 15 $\mathrm{nm}$ nanoparticles.

Acknowledgements: This research has been funded by a number of charitable trusts, the largest donations coming from The James Tudor Foundation, William A Cadbury Charitable Trust, Carol's Smile, The Grace Fry Charitable Trust, The Sobell Foundation, and The Charles and Elsie Sykes Trust. Without their support this research would not have been possible.

\section{References}

1. RANADE V.V., CANNON, J. B., Drug Delivery Systems $3^{\text {rd }}$ ed., CRC Press, Taylor\&Francis Group, 2011, p 13.

2. ALLEN, T. M. and CULLIS, P. R., Advanced Drug Delivery Reviews 65,2013, p. 36.

3. MIGNANI, S., EL KAZZOULI, S., BOUSMINA, M., MAJORAL, J.-P., Advanced Drug Delivery Reviews 65, 2013, p. 1316.

4. DECKER, G., Science 227, 1997, p. 1232.

5. DONATH, E., SUKHORUKOV, G. B., CARUSSO, F., DAVIES, S. A., 
MOHWALD, H., Angew. Chem. Int. Ed. 37, 1998, p. 2201.

6. SUKHORUKOV, G. B., DONATH, E., DAVIES, S., LICHTENFELD, H., CARUSSO, F., POPOV, V. I., MOHWALD, H., Polym. Adv. Technol. 9, 1998, p. 759.

7. ANTIPOV, A. A., SUKHORUKOV, G. B., Advances in Colloid and Interface Science 111, 2004 p. 49.

8. VOLODKIN, D., von KLITZING, R., Current Opinion in Colloid \& Interface Science 19, 2014, p. 25.

9. JABER, J.A., SCHLENOFF, J. B., Langmuir 23, 2007, p. 896.

10. GAO, C., LEPORATTI, S., MOYA, S., DONATH, E., MOHWALD, H., Chem Eur. J. 9, 2003, p. 915.

11. ANTIPINA, M. N., SUKHORUKOV, G. B., Advanced Drug Delivery Reviews 63, 2011, p. 716.

12. PETROV, A.I., VOLODKIN, D. V, SUKHORUKOV, G. B., Biotechnology progress 21, 2005, p. 918.

13. JOHNSTON, A. P. R., READ, E. S., CARUSSO, F., NanoLetters 5 , 2005, p. 953.

14. COOPER, C. L., DUBIN, P. L., KAYITMAZER, A. B., TURKSEN, S. Curr. Opi. Colloid and Interface Sci. 10, 2005, p. 52

15. WONG, H. L., BENDAYAN, R., RAUTH, A. M., LI, Y., WU, X. Y., Adv. Drug Delivery Rev. 59, 2007, p. 491.
16. RIVERA, P., GIL, L. L., DEL MERCATO, P. del-PINO, MUNOZ-JAVIER, A.A. and PARAK, W. J., NanoToday 3, 2008, p. 12.

17 DELCEA, M. MOHWALD, H., SKIRTACH, A. G., Advanced Drug Delivery Reviews 63, 2011, p. 730.

18. KOLENISNIKOVA, T. A., KHLEBTSOV, B. N., SHCHUKIN, D. G. GORIN, D. A., Nanotechnologies in Russia 3, 2008, p. 560.

19. GRIGORIEV, D. O., BUKREEVA, T., MOHWALD H., SHCHUKIN, D. G., Langmuir 24, 2008, p. 999.

20. RIDI, F., BONINI, M., BAGLIONI, P., Advances in Colloid and Interface Science 207, 2014, p. 3.

21. KREFT, O., PREVOT, M., MOHWALD, H., SUKHORUKOV, G. B., Angew. Chem., Int. Ed. 46, 2007, p. 5605.

22. KOLESNIKOVA, T. A., GORIN, D. A., FERNANDES, G., P., KESSEL, S., KHOMUTOV, G. B., FERY, A., SHCHUKIN, D. G., MOHWALD, H., Adv. Funct. Mater. 20, 2010, p. 1189.

23 VOLODKIN, D. V., PETROV, A. I., PREVOT, M. E. SUKHORUKOV, G. B., Langmuir 20, 2004, p. 3398

23. HU, S.-H., TSAI, C.-H., LIAO, C.-F., LIU, D. M., and CHEN, S. Y., Langmuir 24, 2008, p. 11811.

Manuscript received: 6.03 .2017 